\title{
Game-Technical Management Of The Educational Environment
}

\author{
Marina Aleksandrovna Romanova ${ }^{1 *}$, Yulia A. Serebrennikova ${ }^{1}$, Tatiana Fedorenko ${ }^{2}$, \\ Alexander Kaitov ${ }^{1}$, Anna Gavriliuc ${ }^{3}$ \\ ${ }^{1}$ Moscow City University, Moscow, Russia \\ ${ }^{2}$ Sakhalin State University; Yuzhno-Sakhalinsk, Russia \\ ${ }^{3}$ Universitatea Slavona, Chisinau, Respublica Moldova
}

\begin{abstract}
The article presents the results of theoretical research and practical use of game-technical training technologies to enrich the educational environment in a pedagogical university. The need to organize and conduct present research is due to the objective demand for teachers who can master and implement interactive technologies in the educational process, as well as manage them. The authors' goal was to develop a theoretical model for enriching the content of education in a contemporary pedagogical university based on game-technical management. The process of achieving the goal is presented in the article in the form of a description of this model, analysis, and interpretation of the results obtained during testing the model proposed for using to enrich the content of education in the educational environment of the university. A system-forming factor in the concept of educational game-technical management is a methodological procedure specially developed by the authors, which aims at determining the potential of search and research games to solve the problems of enriching the educational environment of a particular educational institution. The necessary conditions for the functioning of this process, presented in the article, will help future executives of educational organizations to assess the potential of game-technical management and the possible risks of its practical implementation.
\end{abstract}

\section{Introduction}

The education modernizing processes, which began at the end of the $20^{\text {th }}$ century, today require a deep review and rethinking. The contemporary labor market dictates the need for meaningful changes in training technologies, and sometimes a complete rejection of those innovations that did not meet expectations. Science-based innovative technologies, based on a deep insight into the essence of the very technology, understanding of the essential functioning mechanisms, and comprehensive analysis and assessment of possible risks of its practical implementation are today at the forefront. The increased demands on the part of the state and parents to the quality of education indicate an objective need for teachers who can master and implement interactive technologies in the educational process, as well as

\footnotetext{
* Corresponding author: romanovam@mgpu.ru
} 
manage them. Therefore, the authors of the present study have attempted to change qualitatively the educational environment of a pedagogical university. The research is based on the idea of recognizing that game management is a pedagogically based management activity, which includes as structural components the development and implementation of interactive technologies in the educational process, as well as their management. At that, the enrichment of the educational environment is considered as a dynamically developing process of progressive changes in the main structural components of the educational organization (content, methods, conditions, regularities, principles, and expected results).

The purpose of the study was to develop a theoretical model for enriching the content of education in a contemporary pedagogical university based on game-technical management.

The theoretical prerequisites for the development of the authors' model were the works of researchers from the USA, Russia, and Germany: J. Renzulli, S.M. Ries, A.I. Savenkov, N.B. Shumakov, and K. Heller. [1-4]. Education content enrichment system, proposed by Renzulli, suggests considering changes in content in terms of time characteristics. The time aspect assumes a trajectory of mutual enrichment: types of content enrichment gradually grow into each other, successively replacing the previous type of enrichment. At this stage, the foundation of educational and research activities is created: the maximum expansion of the student's horizons, identification, and selection of the most productive and attractive type of training. Purposeful development of thinking, improvement of cognitive functions takes place in the team training of activity. If operating in a sense close to the traditional understanding of the learning process, the properties formed at these levels create conditions for the third type of enrichment - the student's own, real research, and training as such $[1,3]$.

The content of the contemporary education, as follows from the studies of Savenkov, should be qualitatively different from the traditional one, have quantitative cognitive and noncognitive predictors of assessment, and be based on two levels of enrichment horizontal and vertical $[2,5]$. When constructing the model and testing it, the data available on the theory and practice of pedagogical modeling and design were taken into account (A.A. Kirsanov, L.M. Fridman, et al.). [6, 7].

\section{Methods}

Experimental verification of the effectiveness of the proposed model was carried out in the course of a multifunctional, systematic, longitudinal study based on two universities.

The study engaged students of the Moscow City Pedagogical University and Sakhalin State University, who were studying in the majors of "Pedagogical education" and "Psychological and pedagogical education" (Primary education profile).

Based on theoretical research [8-14], a theoretical model was developed to enrich the content of education in a contemporary pedagogical university based on game-technical management.

The proposed model is based on a systematic approach to the study of mental phenomena and personality activity, which is well-established in contemporary psychological science [15-17]. The system-forming factor in the model of game-technical management of the educational environment is a methodological procedure specially developed by the authors, aimed at determining the search and research games potential to solve the problems of enriching the educational environment of a particular educational institution. Thus, the theoretical model of enriching the content of education in a contemporary pedagogical university based on game-technical management has a structure that includes three interrelated and mutually dependent components, namely, targetoriented, content-oriented, and estimation component. The target-oriented component involves the formulation and implementation of targets at three levels: 
1. mastering game technologies;

2. implementing game technologies in educational practice;

3. game technology management.

The content-oriented component includes a constructive analysis of the variety of interactive technologies and identification of the search and research games potential, the choice of tools and methods for implementing game technologies in educational practice.

Finally, the estimation component of the model describes predictors of estimating the success of the model operation, both cognitive and noncognitive.

The model also includes the relationships that exist between components (for example, between the target and content, content and estimation, etc.). Understanding and taking these relationships into account largely determines the effectiveness of the model itself.

The role of the teacher in the proposed model has changed significantly in comparison with traditional technologies. The active position belongs to students, and they control the game process of organizing the educational environment, the very learning process, and their individual development trajectory. Such changes are made possible by co-organizing the interaction of participants and creating specific conditions for the emergence of their initiative, and creative solutions for specific educational situations.

The implementation of the model was carried out at two levels - vertical and horizontal. The vertical level included a review of methods, techniques, and means of organizing activities, namely, implementing game-technical training methods in the mastering of key modules of the curriculum.

The horizontal level concerns the direct enrichment of the education content. A systemforming factor in the concept of educational game-technical management is specially developed authors' methodological procedure aimed at determining the potential of search and research games to solve the problems of enriching the educational environment of a particular educational institution. The main conditions for selecting games and game technologies to implement the model at two levels were four main factors:

- $\quad$ enriching an individual's cultural heritage;

- $\quad$ expanding the horizons and enriching the knowledge foundation;

- establishing an atmosphere for creative search;

- encouraging metaphorical thinking in the course of learning.

The paradigm shift in the structure of teachers' activities as future leaders of education in the course of implementing the model of game-technical management of the educational environment has changed due to the inclusion of key game technologies, such as lesson design, student projects (including network projects), grade management, and selfmanagement in the educational process.

\section{Results}

Positive changes were noted in the course of observations and analysis of the implementation in the operating practice of two universities of the proposed model aimed at enriching the content of education in a contemporary pedagogical university based on game-technical management. First of all, the changes affected noncognitive predictors, such as students' perseverance in achieving targets, self-confidence, and focus on achieving goals.

According to authors' observations, game situations that arise in the course of teaching activities of the very students represent a particular value in developing the ability to creatively solve pedagogical and managerial tasks, as well as developing positive motivation. An increase in the level of development of specific qualities of pedagogical thinking (resourcefulness, originality, and variability) was noted during the study. 
Role-playing games and pedagogical cases that simulated typical situations of the educational process in primary school had the greatest effect in training future teachers in pedagogical leadership at all stages of the model implementation. To evaluate the effectiveness of the model, a statistical method was used which allowed comparing two alternative numerical aggregates using $\chi^{2}$ (Pearson's Chi-square). In one of the experimental groups (B), the authors deliberately used the traditional approach. Having identified equal groups of testees in terms of their quantitative composition, the authors offered students a control test. The success of executing the task was assessed at each of the three levels of formedness of organizational actions (operations) during the game quest. Actions and responses were recorded and tabulated.

Table 1. Results of solving the pedagogical case by students of experimental and control groups.

\begin{tabular}{|c|c|c|c|c|}
\hline No. & Groups & $\begin{array}{c}\text { Correct operations } \\
\text { performed }\end{array}$ & $\begin{array}{c}\text { Incorrect operations } \\
\text { performed }\end{array}$ & Total \\
\hline 1. & A (EXP) & 147 & 119 & 266 \\
\hline 2. & B (CONTR.) & 120 & 146 & 266 \\
\hline \multicolumn{2}{|c|}{ Total } & 267 & 265 & 432 \\
\hline
\end{tabular}

Besides, an expert assessment of 30 predictors that reflected the key requirements for teaching activities was conducted. Predictors that reflect the requirements for the teacher's activity at the impact level were rated at one point, while predictors of the interaction level were given two points. Most of the students in the experimental groups had a predominant list of indicators formed at the interaction level.

The convincing data were obtained when analyzing the results of graduates of the Institute of Pedagogy and Psychology of Education of the Moscow City Pedagogical University and the Institute of Psychology and Pedagogy of the Sakhalin State University. In these universities, 254 young professionals having worked at school for one year were surveyed. The leading positions in their teams were occupied by 224 people, among whom 116 had ranking above $75 \%$, while the ranking of 108 ranged from 50 to $75 \%$. At that, the overall job satisfaction index after the first year of teaching was 0.687 .

Game-technical management has made it possible to increase the responsibility of executives and teachers in improving existing programs, as well as developing and implementing new educational programs. They developed the authors' role-playing games, quests, virtual tours, and master classes. The quality of teaching has improved due to the revision of the content of disciplines through the prism of key factors in the selection of games and game technologies for implementing the developed model at two implementation levels.

The organization of the educational environment based on game-technical management technologies allows gaining self-confidence, develop skills that are in demand for professional teachings, such as, constructively negotiate with educational process participants, and quickly establish business contacts with colleagues and parents. Besides, these technologies allow increasing competitiveness, improving the verbal and visual image of the teacher, carrying out cooperation and communication, positioning oneself as a successful designer of the educational environment. 


\section{Discussion}

Most of the changes noted in the course of observations and examinations relate to qualitative changes. The implementation of game technologies and the structural components of the model led to qualitative changes, primarily in the motivation and degree of involvement in the educational activities of teachers and students.

Quantitative indicators of noncognitive predictors tend to increase, while cognitive ones have different expressiveness. A similar pattern was found in the authors' research [...] and correlates with the conclusion derived from research results of A.P. Panfilova: intellectual activity is determined by the motivational component of a person's potential [1].

\section{Conclusion}

Testing the model in the course of training future primary school teachers has shown its effectiveness. The conducted research gives grounds to assert that the teachers' training process at the university will acquire an optimal character if the educational environment is based on the technology of game-technical management. At that, the very learning process is based on the development of students' skills to master and implement interactive technologies in the educational process and manage them. This process represents an integrated system, whose system-forming factor is a theoretical model for enriching the content of education in a contemporary pedagogical university based on game-technical management, and encompasses all the components of their learning and independent pedagogical activities in their dialectical relationship.

The authors see the prospect of further research in the search for ways to assess the potential opportunities of game-technical management, and the possible risks of its practical implementation.

\section{References}

1. J. Renzulli. A model of enriching school education: a practical program to stimulate the giftedness of children. Basic modern concepts of creativity and giftedness. Edited by Bogoyavlenskaya D. B. (Moscow, 1997) 214-242.

2. A. I. Savenkov. A gifted child in a mass school. (Moscow, 2001).

3. Joseph S. Renzulli. Lecture Notes from the 2009 University of Connecticut Neag Confratute. (2009).

4. W. Stern, F. J. Mönks, K. A. Heller und J. S. Renzull. Begabungsforschung und Begabtenförderung: der lange Weg zur Anerkennung: schlüsseltexte. (LIT Verlag, Münster, 2013).

5. A. Savenkov, S.I. Karpova \& E.I. Sukhova. Model of development of children's giftedness in the russian education system. Psychology (Savannah, Ga.) 55 (2) 74-84, (2018).

6. L.M. Friedman. Fundamentals of Problemology. (Librocom, Moscow, 2009).

7. A. A. Kirsanov. Methodological problems of creating a prognostic model of a specialist. (Kazan, 2000) 227.

8. Jean-Louis Berger, Céline Girardet, Cynthia Vaudroz, Marcel Crahay. Teaching Experience, Teachers' Beliefs, and Self-Reported Classroom Management Practices: $A$ Coherent Network 8(1), (2018).

9. Azita Iliya Abdul Jabbar, Patrick Felicia. Gameplay Engagement and Learning in 
Game-Based Learning: A Systematic Review. Educational research review 85(4) 740779, (2015)

10. A. Ganicheva. Teacher-student interaction in the context of a coworking educational environment. [Conf. Teacher-student interaction in the context of university education: theory, technology, management] 645, (2019).

11. A. P. Panfilova. Game Engineering Management. Interactive technologies for training and organizational development of personnel: textbook. (IVESEP, Znanie, St. Petersbur, 2003) 536.

12. I. E. Sarafanova. A model for the formation of organizational and managerial competence of a manager in a university based on the game-technical method. Yaroslavl Pedagogical Bulletin 4129 - 134, (2015).

13. L. Pannese \& M. Carlesi. Games and learning come together to maximize effectiveness: The challenge of bridging the gap. British Journal of Educational Technology 38(3) 438-454, (2007).

14. S.L. Bowman. The Functions of Role-Playing Games: How Participants Create Community, Solve Problems and Explore Identity, Publication City. (McFarland \& Co Inc., Country Jefferson, NC, United States,2010) 216.

15. C. Montag, J.D. Elhai. A new agenda for personality psychology in the digital age? Personality and Individual Differences 147 128-134, (2019).

16. A.L. Smolka et al. Vygotsky's Theoretical and Conceptual Contributions to Qualitative Research in Education. Oxford Research Encyclopedia of Education. (2019). URL: https://oxfordre.com/education/ view/10.1093/acrefore/9780190264093.001.0001/acrefore9780190264093-e-511 Accessed 15.09.2019.

17. I. Letina, S. Liu, N. Netzer. Delegating performance evaluation. Theoretical Economics 15(2) 477-509(2020). 